\title{
Male field cricket song reflects age, allowing females to prefer young males
}

\author{
L. Verburgt*, M. Ferreira, J.W.H. Ferguson \\ Department of Zoology and Entomology and Centre for Environmental Studies, University of Pretoria
}

\section{A R T I C L E I N F O}

\section{Article history:}

Received 10 June 2010

Initial acceptance 20 July 2010

Final acceptance 9 September 2010

Available online $\mathrm{xxx}$

MS. number: 10-00417R

\section{Keywords:}

calling song

female preference

Gryllus bimaculatus

senescence

sexual selection
Sexual selection often involves female preference for males of a certain age, and a body of theory predicts preference for old males. We measured a comprehensive set of traits from the acoustic sexual display of male field crickets, Gryllus bimaculatus, and found that nearly all song traits changed predictably as males aged, involving a general slowing down of the wing movements during song production. Our female preference experiments indicated a strong and repeatable preference for the songs of young males, contradicting the existing literature, which argues that female crickets prefer older males on the basis of changes in song carrier frequency. Rather, female preference for young male song was determined by its high energetic quality. We develop the 'old flight muscle' hypothesis, arguing that age-related degradation of stridulatory muscle performance is likely to result in the observed changes with age. Secondary sexual characters may be subject to oxidative somatic degradation suggesting that, when males provide only sperm, females should prefer the sexual displays of young males. Our results support new modelling approaches and a growing body of empirical evidence suggesting that old males are not always preferred by females.

(c) 2010 The Association for the Study of Animal Behaviour. Published by Elsevier Ltd. All rights reserved.
The age of a potential mate is an important trait, which can influence sexual selection. The 'good genes' model of sexual selection (Zahavi 1975) predicts that if the genetic characteristics required to survive to an old age in the current environment are heritable, then females should prefer older males as they have demonstrated their viability (Trivers 1972; Halliday 1978, 1983) and are likely to carry fewer deleterious alleles (Manning 1985). Modelling approaches attempting to explain the evolution of female preference for males (Hansen \& Price 1995; Kokko \& Lindström 1996; Kokko 1998; Beck \& Powell 2000; Beck et al. 2002; Beck \& Promislow 2007), as well as empirical studies (reviewed in Brooks \& Kemp 2001), have demonstrated different outcomes: female preference may evolve for young, intermediate-aged or old males. It is therefore no longer universally accepted that older males always provide good genes.

When females are able to determine a male's age, preference for younger males is predicted to evolve according to Beck \& Promislow's (2007) model, assuming an increase in the number of deleterious mutations in the germline as a male ages. This model is of particular relevance in species where females obtain only sperm from a mating and no other direct benefits: older males are expected to be inferior because their fertility is diminished either through poor-quality sperm (affecting offspring survival) or insufficient viable sperm numbers. Velando et al. (2008) proposed that oxidation

\footnotetext{
* Correspondence: L. Verburgt, Centre for Environmental Studies, Room 2-1 Geography, University of Pretoria, Pretoria 0001, South Africa.

E-mail address: lverburgt@zoology.up.ac.za (L. Verburgt).
}

of DNA in the germline is a prominent force in the evolution of mate choice and sexual signalling. If the amount of oxidative DNA damage is correlated with the expression of a secondary sexual character, females may avoid the negative heritable consequences by avoiding sperm damaged by oxidation. The hypothesized mechanism for this is as follows. Oxidation of DNA in the germline takes place with age through oxidative stress (oxidative stress hypothesis, Sohal et al. 2002; but see Buffenstein et al. 2008). If the secondary sexual traits preferred by females are honest indicators of male quality, increasing somatic oxidative damage with age will increasingly have a negative effect on the expression of these traits. In line with the predictions of Beck \& Promislow (2007) and Velando et al. (2008), Hoikkala et al. (2008) showed that both reproductive success and the quality of sexually selected song in Drosophila montana males decrease with male age. Female $D$. montana are therefore able to avoid 'bad genes' by preferring younger males on the basis of the courtship song.

Because acoustic signals are secondary sexual traits often under sexual selection (Andersson 1994) these systems can provide insight into the evolution of female preference. Field crickets (Orthoptera: Gryllidae) are a particularly well-studied taxon that produce acoustic signals by scraping their tegmina (forewings) together. The resulting sound usually has a distinct temporal and spectral structure for each species (Gerhardt \& Huber 2002). While certain characteristics of the sound such as the syllable period are thought to be species recognition traits (Schildberger et al. 1989; Ferreira \& Ferguson 2002), other song traits (e.g. carrier frequency, intersyllable interval, chirp rate) are thought to be sexually selected because they are correlated 
with a male trait (e.g. body size) preferred by females (Simmons \& Ritchie 1996; Gerhardt \& Huber 2002; Scheuber et al. 2003a, b; Jacot et al. 2007; but see Verburgt \& Ferguson 2010). For several cricket species it has been shown that certain male song traits change with age (Table 1 ), potentially allowing females to select males of preferred age based on song traits.

An interspecies comparison of age-related effects on cricket song traits where nutritional condition was not manipulated does not reveal a consistent effect on a particular song trait (Table 1). Moreover, different studies on the same species have found contradictory results (e.g. an age-related effect on carrier frequency for Gryllus campestris: Simmons 1995; Jacot et al. 2007; Table 1), usually explained by differences in experimental design. It is therefore difficult to make generalized predictions of how male age is expected to affect mating behaviour.

Jacot et al. (2007) used a longitudinal experimental design (same animals measured when young and old) to demonstrate that for male field crickets, G. campestris, age is predictable from the songs they produce The carrier frequency (frequency of greatest power, hereafter FQ), syllable number (syllables per chirp) and chirp length of old males were, on average, lower than for young males. Jacot et al. (2007) focused their discussion on the change in FQ (nominally $5 \mathrm{kHz}$ ), which was, on average, $80 \mathrm{~Hz}$ lower for old males, and suggested that females preferentially select older males because they prefer lower FQ (Scheuber et al. 2004). However, they did not experimentally demonstrate that females were able to detect such a small change in FQ or that the older male song was preferred. Verburgt \& Ferguson (2010) recently challenged the current emphasis on song FQ in studies on grylline crickets and showed that female preference for song FQ at the population level is broad with little preference variation between 4 and $5 \mathrm{kHz}$ (see also Verburgt et al. 2008). Therefore, despite the fact that male cricket song does change with age (Table 1), it is unclear whether females can detect these changes and whether they show a particular directional preference based on these changes.

Finally, within the context of the work by Beck \& Promislow (2007) and of Velando et al. (2008), it is not clear why female crickets should prefer older male crickets, since males of many species usually provide only sperm during mating. In Gryllus bimaculatus males, reproductive success as measured by progeny production per mating decreases significantly with age (Simmons 1988). Nevertheless, several studies on grylline crickets have demonstrated female preference for older males (e.g. G. veletis and G. pennsylvanicus: Zuk 1987) although no calling song traits in these species varied with age (Cade \& Wyatt 1984; Ciceran et al. 1994).

In acoustic signalling species it is not only the song structure (temporal and spectral traits) that is of importance but also the duration (time spent calling) and timing (temporal calling pattern) of the song (Walker 1983; Bertram \& Johnson 1998; Bertram 2000; Jacot et al. 2008). Old and very young male Gryllus integer spent less time calling per night than intermediate-aged males, while old males initiated calling earlier in the evening (Bertram 2000). When investigating the effects of age on male song production, it is therefore important to describe changes in the signalling intensity and timing thereof.

Our aims in this study were threefold. First, we investigated how calling songs change with age by recording male G. bimaculatus every night for the duration of their adult lives, and by recording a large array of male song traits, thus improving on the longitudinal experimental design (Jacot et al. 2007). Second, we used phonotaxis

Table 1

A summary of literature on the effect of age on calling song traits for crickets where nutritional condition was not manipulated (Orthoptera; Family Gryllidae)

\begin{tabular}{|c|c|c|c|c|}
\hline Species & Song trait(s) & Methods & Effect of age & Source \\
\hline Acheta domesticus & $\begin{array}{l}\text { Amplitude, number of syllables per chirp, frequency } \\
\text { and interchirp interval }\end{array}$ & $\mathrm{X}$ & None & Gray 1997 \\
\hline $\begin{array}{l}\text { Gryllus veletis \& } \\
\text { G. pennsylvanicus }\end{array}$ & Onset of calling (age), mean calling time per day & $\mathrm{L}$ & None & Cade \& Wyatt 1984 \\
\hline Gryllus bimaculatus & $\begin{array}{l}\text { Carrier frequency, q3 tuning, chirp duration, chirp interval, chirp rate, } \\
\text { syllables per chirp, syllable duration, syllable interval, syllable rate, } \\
\text { coefficient of variation for each of the aforementioned traits }\end{array}$ & & $\begin{array}{l}\text { Coefficient of variation } \\
\text { for syllable rate increased }\end{array}$ & Simmons \& Zuk 1992 \\
\hline Gryllus campestris & $\begin{array}{l}\text { Carrier frequency, chirp rate, syllables per chirp, chirp length, } \\
\text { interchirp duration, chirp energy }\end{array}$ & $\mathrm{L}$ & $\begin{array}{l}\text { Carrier frequency, } \\
\text { syllables per chirp \& } \\
\text { chirp length decreased }\end{array}$ & Jacot et al. 2007 \\
\hline Gryllus campestris & Carrier frequency & $\mathrm{X}$ & None & Simmons 1995 \\
\hline Gryllus integer & Time spent calling, temporal calling pattern (start, stop \& mean time) & $\mathrm{L}$ & $\begin{array}{l}\text { Time spent calling } \\
\text { decreased, start and } \\
\text { mean time decreased }\end{array}$ & Bertram 2000 \\
\hline Gryllus integer & Number of syllables per trill & $\mathrm{X}$ & None & Gray \& Cade 1999 \\
\hline Gryllus integer & $\begin{array}{l}\text { Syllable rate, syllable length, intersyllable length, syllable duty cycle, } \\
\text { peak frequency, syllables per trill, trill length, intertrill interval, } \\
\text { trill duty cycle, missed syllables }\end{array}$ & $\mathrm{X}$ & None & Martin et al. 2000 \\
\hline Gryllus integer & Syllable rate, missed syllables per trill & $\mathrm{X}$ & None & Souroukis et al. 1992 \\
\hline Gryllus pennsylvanicus & $\begin{array}{l}\text { Syllable rate, number of syllables per chirp, interchirp } \\
\text { duration or chirp duration }\end{array}$ & $\mathrm{L}$ & None & Ciceran et al. 1994 \\
\hline Gryllus rubens & Syllable rate & $\mathrm{L}$ & None & Walker 2000 \\
\hline Oecanthus nigricornis & Syllable period, syllable duration, frequency & $\mathrm{X}$ & $\begin{array}{l}\text { Syllable duration } \\
\text { decreased }\end{array}$ & Brown et al. 1996 \\
\hline Teleogryllus commodus & Mean nightly calling effort & $\mathrm{L}$ & None* & Zajitschek et al. 2009 \\
\hline Teleogryllus oceanicus & $\begin{array}{l}\text { Duration of long chirp, no. of syllables in long chirp, } \\
\text { syllable rate in long chirp, syllable duration in long chirp, } \\
\text { intersyllable interval in long chirp, duration of short chirp, } \\
\text { no. of chirps in short chirp, chirp rate in short chirp, } \\
\text { syllable duration in short chirp, intersyllable interval in } \\
\text { short chirp, interchirp interval in short chirp, total song duration, } \\
\text { carrier frequency in short chirp, carrier frequency in long chirp, } \\
\text { proportion of song that is long chirp }\end{array}$ & $\mathrm{X}$ & None & Walker \& Cade 2003 \\
\hline
\end{tabular}

Methods indicate longitudinal (L) or cross-sectional (X) experimental design.

* No effect of age on calling effort was found when individuals that never called were excluded from the analysis. 
experiments to determine whether females prefer the songs of older males. Third, we tested phonotactically whether females can detect the spectral differences in calling song that have been discussed in the literature ( $<100 \mathrm{~Hz}$ in $\mathrm{FQ})$.

\section{METHODS}

\section{Animals}

Penultimate-instar field crickets, G. bimaculatus, reared in captivity were housed in separate 2-litre containers. High-quality food (Pronutro and fish flakes containing 16\% and 43\% protein, respectively) and water were provided ad libitum throughout the experiment. The date of final moult was recorded. Both males and females were virgins (inseminated G. bimaculatus females do not show phonotaxis, Loher et al. 1992). Females were continuously exposed to male songs from the captive colony. Males were recorded between May 2002 and September 2006. Female preference experiments were performed from July to November 2009.

\section{Male Song}

\section{Song recording}

Males were kept singly in a gauze container $(11 \times 11 \mathrm{~cm}$ and $12 \mathrm{~cm}$ high) with a cardboard floor, placed in a sound-damped recording chamber $\left(25 \pm 1{ }^{\circ} \mathrm{C}\right) 9$ days after the final moult. A 12:12 h light:dark regime was implemented using an $8000 \mathrm{mCd}$ light-emitting diode in the roof of each chamber. Male calling song was recorded for $30 \mathrm{~s}$ several times per $24 \mathrm{~h}$ using a Behringer XM200S dynamic microphone $(50 \mathrm{~Hz}-10 \mathrm{kHz} \pm 3 \mathrm{~dB}$; Behringer Spezielle Studiotechnik GmbH, Willich-Münchheide II, Germany). We recorded each male, without handling it, between putting it in the chamber on day 9 and removing it on day 51 (or when it died). After a male had been calling continuously for $5 \mathrm{~min}$, its calling song was recorded ( $30 \mathrm{~s}$, sampling rate $=22050 \mathrm{kHz}$ ) directly to a computer using custom software (J.W. H. Ferguson). The number of seconds for which calling song was produced by each male was recorded automatically by an electret microphone on an hourly basis throughout the day. We analysed three randomly chosen consecutive chirps per day from a recording after initially filtering the recordings (high-pass filter $=1 \mathrm{kHz}$ ). The temporal song traits measured were number of syllables per chirp, syllable duration (SD), syllable period (SP) and intersyllable interval (ISI) for every syllable; and chirp duration (CD), chirp period (CP) and interchirp interval (ICI) for every chirp (see Ferreira \& Ferguson 2002). We also calculated duty cycle as a measure of the amount of sound per unit time as follows:

Duty cycle $(\%)=\frac{\sum_{i=1}^{k} \text { Syllable duration }}{\text { Chirp period }} \times 100$

where $k=$ the number of syllables. Spectral traits measured were carrier frequency (FQ; i.e. emphasized or peak frequency) and bandwidth (BW; $10 \mathrm{~dB}$ below peak frequency) using fast Fourier transform. Although our animals were not maintained in a controlled position relative to the microphone (necessary for accurate amplitude measurements), we were still able to estimate the song amplitude of a male's song because we obtained multiple recordings ( $30 \mathrm{~s}$ each) for each male per $24 \mathrm{~h}$ (up to eight) and we selected the recording with the greatest amplitude for that $24 \mathrm{~h}$ period. This meant that changes in amplitude within the recording chamber caused by positional differences of the male were minimized. Furthermore, to control for differences between microphones and structural arrangements within the recording chamber, we calculated the relative amplitude of a male's recording for each night. This was achieved by dividing the amplitude of each recording of a male by the mean amplitude of all his recordings. All song traits were measured with custom software (J. W. H. Ferguson).

\section{Data analysis}

SD, SP and ISI were measured for each syllable in a chirp (3-6 syllables/chirp). A syllable-level analysis was performed using ANCOVA to determine whether each syllable within a chirp was affected similarly by age.

Because the body size of a cricket does not change once the exoskeleton hardens after its final moult (Zajitschek et al. 2009), there was only a single body size observation for each individual but many different observations for a particular calling song trait during the experiment, complicating an analysis of the effects of body size. To determine whether body size influenced any of the calling song traits measured, we first regressed each calling song trait on age (days) for every individual and obtained both the slope and intercept of this regression. This allowed the determination of the relationships between the slope and intercept and the body size of an individual. To detect effects of body size, we separately regressed the above slope and intercept on body size.

The mean value for each calling song trait was calculated per day and subjected to a linear regression analysis on male age (days). Sometimes males did not call sufficiently within a day to be successfully recorded ( $<5$ min continuous calling) or died before 50 days of age, resulting in different sample sizes per day (range 10-25). All data were tested for normality before applying a linear regression. Using circular statistics on the hourly calling activity data, we calculated the peak or acrophase of calling activity for each male on each day by calculating the mean vector and the dispersion around this peak using relative vector length ( $r$; Batschelet 1981).

\section{Female Preference}

\section{Acoustic stimuli}

Experiment 1. To determine whether females prefer the songs of older or younger males, we compared young males (10-12 days after final moult) with old males (48-50 days old). We first calculated the mean song trait values for each male when young (10-12 days) and old (48-50 days), respectively, and then pooled these data by age category (young and old) to calculate the mean song trait values for young and old males (Table 2). Customdesigned software (L. Verburgt) was then used to generate two sound files containing cricket song, each sound file conforming to the mean song trait values for young and old males, respectively (Table 2). Because the mean values for each song trait were generated from different animals, the temporal traits did not sum up correctly. For example, if the SD of $22.5 \mathrm{~ms}$ is summed with the ISI of $17.4 \mathrm{~ms}$ observed for the young males, an SP of $39.9 \mathrm{~ms}$ is expected rather than the observed SP of 34.9 ms (Table 2). Priority was given to SD over ISI when creating the sound files because it is the sound production portion of the stimulus that is likely to be evaluated by females and not the silent portions. ISI was therefore adjusted to reflect the observed SP, with the two sound files generated having ISIs of $12.4 \mathrm{~ms}$ and $19.4 \mathrm{~ms}$ for the young and old sound files, respectively. Each syllable had a 2 ms linear rise-fall time and was frequency modulated in a linear manner according to the mean bandwidth value obtained for young and old males, respectively.

Experiment 2. To determine whether females can discriminate between songs differing in FQ by approximately $80 \mathrm{~Hz}$, we generated two sound files with identical temporal traits but differing only in FQ. We used the same temporal traits as for the young male 
Table 2

Effects of age (10-50 days) on the calling song traits for 25 male Gryllus bimaculatus

\begin{tabular}{|c|c|c|c|c|c|c|}
\hline Calling song trait & 10-12 days & $48-50$ days & $F_{1,39}$ & Slope & $R^{2}$ & $P$ \\
\hline Bandwidth $(\mathrm{Hz})$ & $317.2 \pm 12.5$ & $296.8 \pm 13.1$ & 19.69 & -1.35 & 0.32 & $<0.0001$ \\
\hline Calling activity dispersion $\left(r^{*}\right)$ & $0.73 \pm 0.01$ & $0.64 \pm 0.03$ & 22.73 & -0.002 & 0.35 & $<0.0001$ \\
\hline Carrier frequency $(\mathrm{Hz})$ & $5089.7 \pm 16.6$ & $5007.1 \pm 25.2$ & 43.35 & -2.59 & 0.51 & $<0.0001$ \\
\hline Chirp duration (ms) & $121.6 \pm 2.1$ & $131.7 \pm 1.8$ & 67.53 & 0.44 & 0.63 & $<0.0001$ \\
\hline Chirp period (ms) & $313.1 \pm 7.9$ & $384.8 \pm 2.2$ & 171.27 & 1.83 & 0.81 & $<0.0001$ \\
\hline Daily calling activity (h) & $4.46 \pm 0.42$ & $3 \pm 0.41$ & 28.53 & -0.045 & 0.41 & $<0.0001$ \\
\hline Duty cycle (\%) & $26.9 \pm 0.1$ & $17.0 \pm 0.9$ & 156.24 & -0.0024 & 0.80 & $<0.0001$ \\
\hline Interchirp interval (ms) & $191.4 \pm 7.5$ & $253.3 \pm 3.0$ & 81.43 & 1.40 & 0.67 & $<0.0001$ \\
\hline Intersyllable interval (ms) & $17.4 \pm 0.6$ & $23.6 \pm 0.7$ & 160.62 & 0.18 & 0.80 & $<0.0001$ \\
\hline Peak of calling activity (h) & $2.66 \pm 1.24$ & $1.55 \pm 0.13$ & 0.04 & -0.002 & 0.001 & 0.84 \\
\hline Pulses per chirp & $3.6 \pm 00$ & $4.0 \pm 0.1$ & 60.48 & 0.01 & 0.60 & $<0.0001$ \\
\hline Relative amplitude & $1.15 \pm 0.01$ & $0.79 \pm 0.02$ & 78.86 & -0.001 & 0.66 & $<0.0001$ \\
\hline Syllable duration (ms) & $22.5 \pm 0.1$ & $15.7 \pm 0.9$ & 493.77 & -0.18 & 0.92 & $<0.0001$ \\
\hline Syllable period (ms) & $34.9 \pm 0.1$ & $35.1 \pm 0.1$ & 5.56 & 0.01 & 0.10 & 0.02 \\
\hline
\end{tabular}

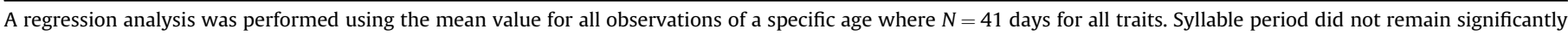
affected by age after a Bonferroni correction $(\alpha=0.0036)$. The mean \pm SEM trait values for both young (10-12 days) and for old males $(48-50$ days) are presented.

* $r=$ relative vector length.

song of experiment 1, but the high-frequency sound file (HighFQ) was generated using the FQ of the young male song $(5089.7 \mathrm{~Hz}$ ) while the low-frequency sound file (LowFQ) was generated using the FQ of the old male song $(5007.1 \mathrm{~Hz})$. These two sound files therefore only differed in FQ and were not frequency modulated as in experiment 1 , to prevent frequency changes (the glissando) within a syllable affecting female preference. Each syllable had a 2 ms linear rise-fall time.

Sound was played back through amplified speakers (Behringer Truth B2030A) that were calibrated with an SPL meter (Adastra 952.425 ) to a sound intensity of $80 \mathrm{~dB}$ SPL (re. $2 \times 10^{-5} \mathrm{~Pa}$ ) at the starting position of the female.

\section{Experimental procedure}

Female preference was determined through simultaneous choice trials in an arena housed within a large anechoic room $(>2 \mathrm{kHz})$ with infrared video surveillance (three cameras). A female was placed in a sound-permeable holding chamber (Fig. 1), the room vacated and the lights turned off, leaving only infrared light from the video equipment. After $30 \mathrm{~s}$ of silence, different stimuli were played back from both speakers simultaneously, each speaker playing either the young or the old song for experiment 1 or the HighFQ or LowFQ song for experiment 2 . Speakers were positioned $2 \mathrm{~m}$ from the starting point of the female and separated by $60^{\circ}$ (Fig. 1). After $30 \mathrm{~s}$ of stimuli playback, a trapdoor on the holding chamber was remotely removed (via a pulley system) allowing the female to leave the chamber and move towards the preferred stimulus. The tunnel attached to the chamber (Fig. 1) forced females to move exactly on the middle line between the two speakers at the beginning of the trial, thereby allowing them to evaluate both stimuli at the same sound intensity (SPL) for a longer period than when we just removed the chamber. Furthermore, the tunnel ensured that each female began the trial at the same position and thereby limited the influence of sound intensity differences on female choice caused by positional differences at the start of the trial. Female choice was defined to have occurred when the female entered the circular area (radius $=25 \mathrm{~cm}$ ) around a speaker following clear phonotaxis. The duration (s) taken for a female to make a choice was recorded. A trial was aborted if a female moved directly away from the speakers (i.e. walked behind the starting position) or if she did not show clear phonotaxis (randomly walking around).

Females were exposed to only one of the experiments (young versus old or HighFQ versus LowFQ) after reaching 10 days of age. Because female preference generally has low repeatability (Bell et al. 2009; but see Verburgt et al. 2008), each female was exposed to four choice trials, two per night and on two consecutive nights. The speaker from which each stimulus was played was randomly determined for the first trial and thereafter alternated for every consecutive trial. The two trials on the same night were at least 10 min apart. Experimental trials were conducted during the normal activity period at night. The pronotum area (width $\times$ length) of each female was recorded following completion of all four trials.

\section{Data analysis}

The female preference experiments yielded binary data in a nested repeated-measures design, where trial was nested within day, which was nested within female identity (ID). To analyse the female choice data, we first performed a Fisher's exact test to determine the effect of trial and day on choice and then we analysed the choice data using a simple method relying on the calculation of a preference score. Females preferring the song of young males were given the binary value of 1 (preference for old $=0$ ). Similarly, females preferring HighFQ were given the binary value of 1 (preference for Low$\mathrm{FQ}=0$ ). A preference score was calculated for each female by taking the mean value of the scores for all four of her trials. For example, preference for old male song (0) in three of four trials would yield a preference score of 0.25 . The null hypothesis for both experiments was that females do not discriminate between the two different stimuli, which would yield an expected preference score of 0.5 reflecting random choice. The population of preference scores for each experiment was then compared to the expected preference score of the null hypothesis (0.5) using a Wilcoxon signed-ranks test. A significant difference between observed and expected preference scores, where the mean population preference score was greater than expected (0.5), would indicate preference for young male song (experiment 1) or HighFQ (experiment 2). Conversely, a mean population preference score significantly smaller than expected $(0.5)$ would indicate preference for old male song (experiment 1 ) or LowFQ (experiment 2). The time taken to make a choice was compared between experiments using a $t$ test for independent samples.

All statistical tests were performed using either $\mathrm{R}$ version 2.11 .1 (R Development Core Team 2010) or Statistica version 7.0 (Statsoft Inc. Tulsa, OK, U.S.A.) with $\alpha=0.05$. All reported values are mean \pm SEM.

\section{RESULTS}

Effect of Body Size on Male Song

None of the slopes of the within-individual regressions of the 14 calling song traits on age were related to body size (Spearman rank 
(a)

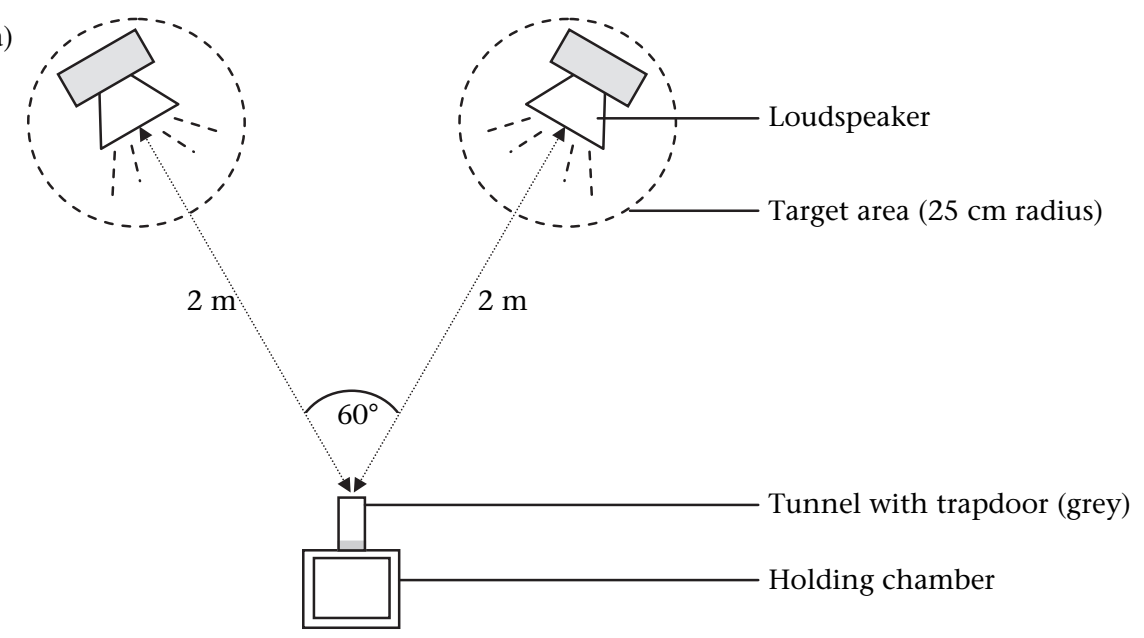

(b)

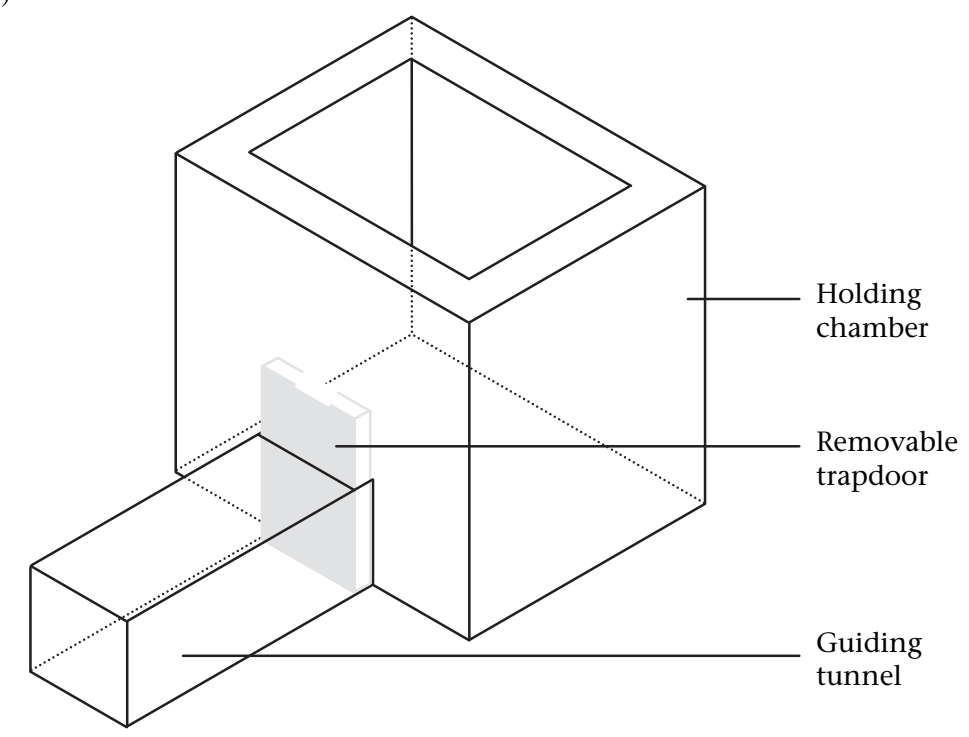

Figure 1. (a) Experimental arrangement of the arena inside the anechoic room used to determine female cricket, Gryllus bimaculatus, preference for different male songs. (b) Close-up of the holding chamber constructed from sound-permeable plastic.

correlation: $\left.r_{\mathrm{S}}<-0.31, N=25, P<0.14\right)$, while the intercept for chirp duration $\left(r_{\mathrm{S}}=0.43, N=25, P=0.03\right)$ and calling activity $\left(r_{\mathrm{S}}=0.50, N=25, P=0.01\right)$ were significantly related to body size. To understand these relationships better, we calculated a mean lifetime value for both chirp duration and daily calling activity for each individual and separately regressed each of these on body size. Mean lifetime calling activity was significantly related to body size $\left(F_{1,23}=6.90, R^{2}=0.20, P=0.015\right.$; Fig. 2$)$ after a Bonferroni correction $(\alpha=0.025)$ while mean lifetime chirp duration was not $\left(F_{1,23}=4.63, R^{2}=0.13, P=0.042\right)$.

\section{Effect of Age on Male Song}

SD differed significantly between syllables within a chirp (e.g. for day $17, N=25$; repeated measures ANOVA: $F_{2,48}=31.67, P<0.001$ ) because the first syllable is always slightly shorter than the others. Despite between-syllable differences, an ANCOVA revealed that SD $\left(F_{3,119}=429.5, \mathrm{P}<0.001\right), \quad \mathrm{SP} \quad\left(F_{3,78}=22.5, \quad P<0.001\right)$ and $\mathrm{ISI}$ $\left(F_{3,78}=123.6, P<0.001\right)$ of each syllable were affected similarly by age because the age*syllable interaction, and therefore the slopes, did not differ significantly (age effect: SD: $t=10.92, P<0.001$; SP: $t=0.19, \quad P>0.05 ;$ ISI: $t=5.30, P<0.001$; syllable effect:

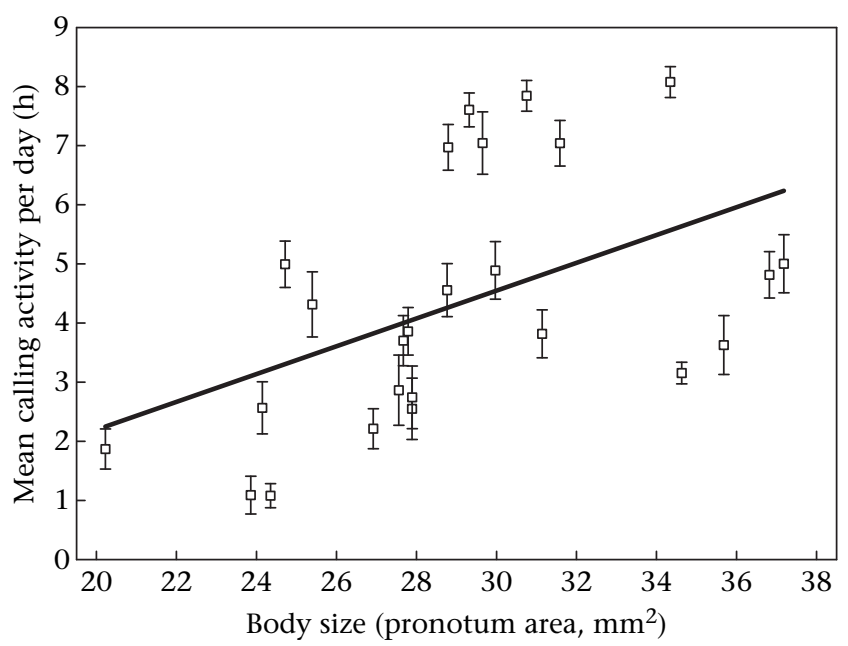

Figure 2. Relationship between mean calling activity per day (h) and body size (pronotum area, $\mathrm{mm}^{2}$ ) for 25 male Gryllus bimaculatus. Error bars represent \pm 1 SEM. 
SD: $t=6.34, P<0.001$; SP: $t=1.65, P>0.05$; ISI: $t=0.69, P>0.05$; age*syllable interaction: SD, SP and ISI: $t<1.94, P>0.05$ ). Since the effect of age was similar across all syllables within a chirp and a syllable-level analysis did not yield any additional information, we present chirp-level analyses that comprise the mean value for all syllables within a chirp.

Except for the daily time of peak calling activity (acrophase) and SP, highly significant linear relationships were found between all calling song traits and male age (Table 2). In general, the energetic investment in the songs decreased as the animals aged; syllable duration, amplitude and calling bout duration decreased while the silent portions of the song (ISI, ICI) increased in duration. Figure 3 illustrates some of these relationships while Fig. 4 shows the circadian pattern of calling activity, as well as the intensity and dispersion thereof for young (10-12 days) and old (48-50 days) males, respectively. Figure 5 shows the oscillograms of the calling song for an exemplar male at three different ages. For duty cycle calculated separately for chirps of different syllable number (Fig. 3d), an ANCOVA $\left(F_{3,117}=113.3, P<0.001\right)$ showed a significant effect of age $(t=2.37, P<0.05)$, a significant effect of syllable $(t=9.48, P<0.001)$ and a significant interaction term (syllable*age) indicating different slopes $(t=4.79, P<0.001)$.

\section{Female Preference}

\section{Experiment 1}

There was no effect of day or trial on female choice (Fisher's exact test: odds ratio $=0.992, P=1)$. Females chose the young male song in 76 of the 84 trials indicating a strong, repeatable and significant preference for young male song (Wilcoxon signed-ranks
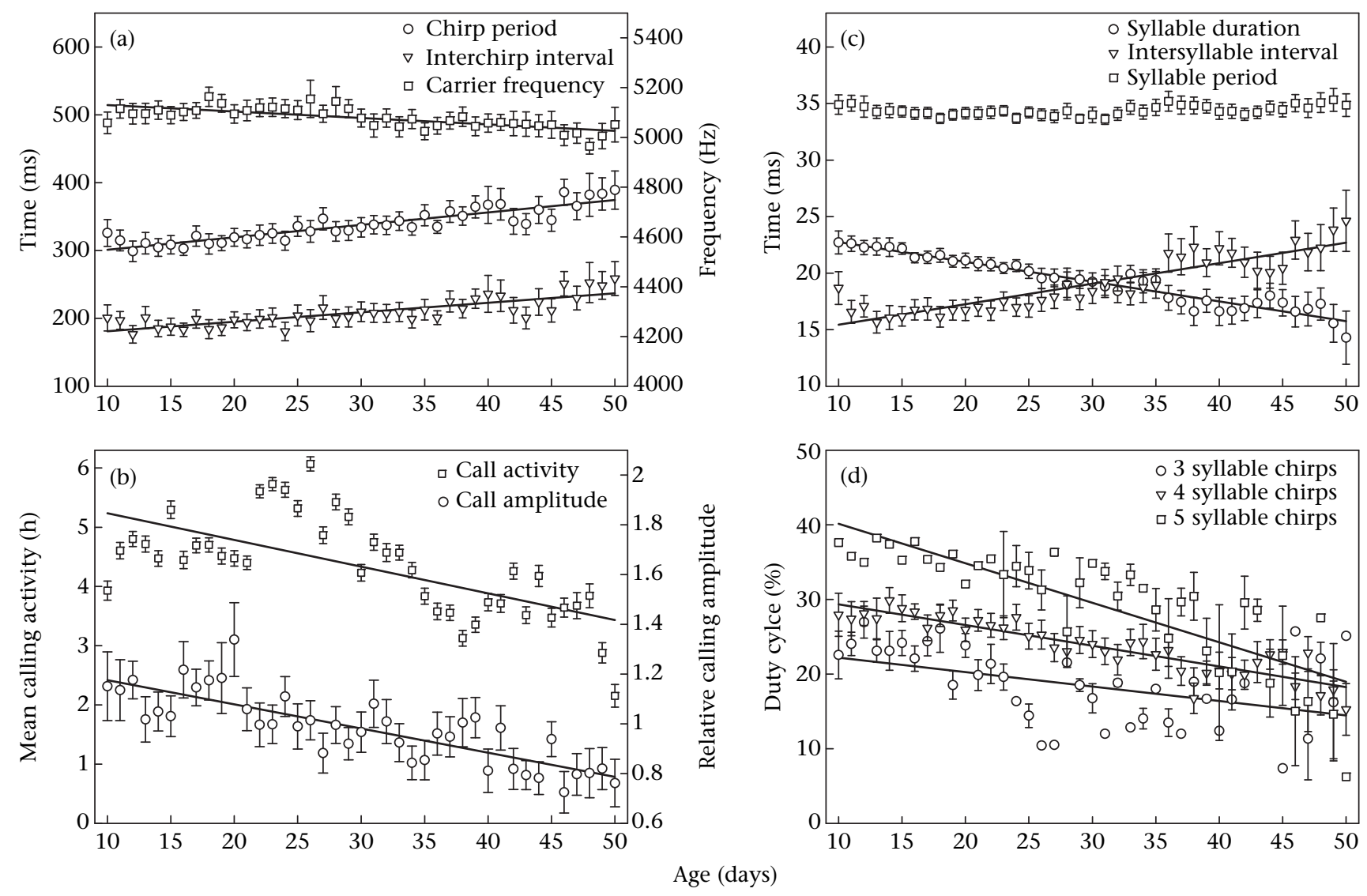

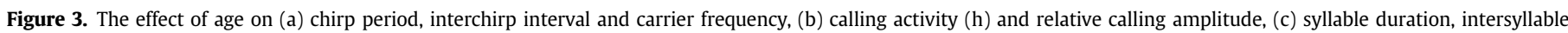

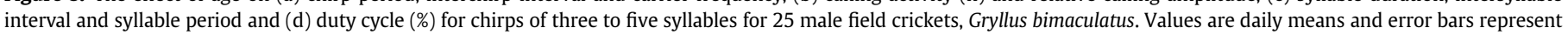
\pm 1 SEM. 

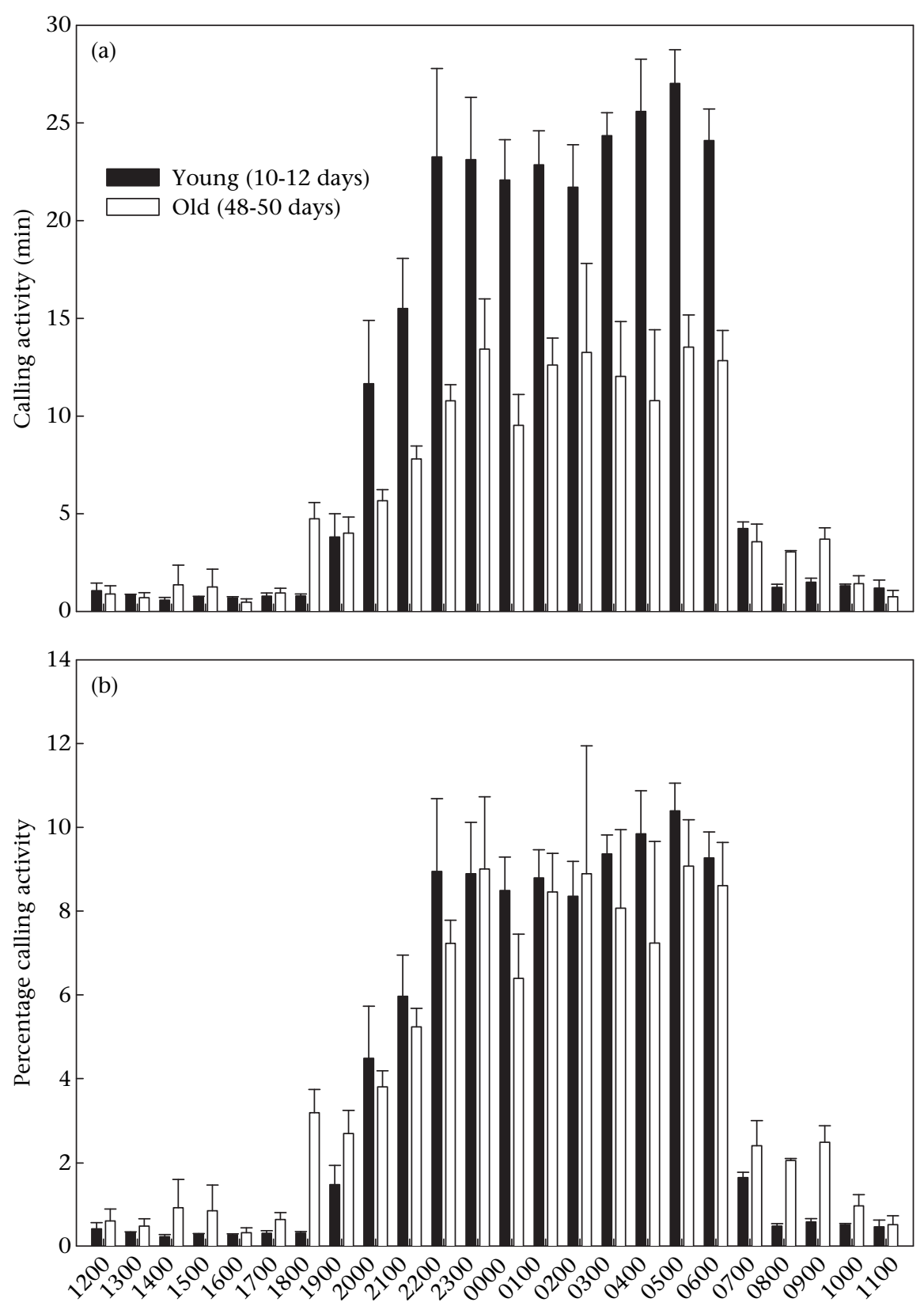

Time (hours)

Figure 4. (a) Hourly and (b) percentage of song production by young $(N=25)$ and old $(N=17)$ male field crickets, Gryllus bimaculatus. Values are means and error bars represent +1 SEM.

chirp duration $(\mathrm{CD})$, all song traits showed a linear age-related decline in energetic quality.

There is strong evidence that the age-related changes in male song that we observed are brought about by a decreased efficiency of the flight muscles caused by senescent physiological changes. During stridulation, males scrape the plectrum of the left tegmen against the file (ventral side of the $\mathrm{Cu} 2$ vein) of the right tegmen and the impact rate of the plectrum on the teeth of the file determines the FQ of the acoustic signal produced, with each oscillation caused by a tooth impact (Prestwich \& Walker 1981; Elliot \& Koch 1985; Koch et al. 1988). It has been suggested that this impact rate is regulated by the resonating properties of the tegmen (the file and plectrum act as an escapement mechanism) and that this rate is nearly constant during the sound-producing tegmen closure (clock-escapement model: Elliot \& Koch 1985; Koch et al. 1988; Bennet-Clark \& Bailey 2002), therefore producing a consistent FQ.

Koch et al. (1988) and van Wyk \& Ferguson (1995) showed that calling song FQ of both $G$. campestris and G. bimaculatus is significantly positively related to the calling temperature. Since the shortening velocity and muscle power output of insect flight muscle is strongly dependent on temperature (Marden 1995; Chown \& Nicolson 2004), low temperatures result in lower tooth impact rates and song FQ (e.g. Prestwich \& Walker 1981). This effect of temperature on calling song FQ is expected to be small (Koch et al. 1988; van Wyk \& Ferguson 1995) because the clock-escapement mechanism regulates the wing closing speed relatively well (Elliot \& Koch 1985; Bennet-Clark \& Bailey 2002). We argue that, similarly to the effect of temperature, a diminished force, resulting 
(a) 10 days

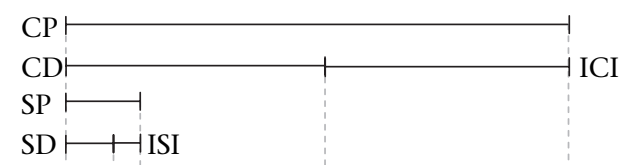

(b) 22 days

(c) 42 days
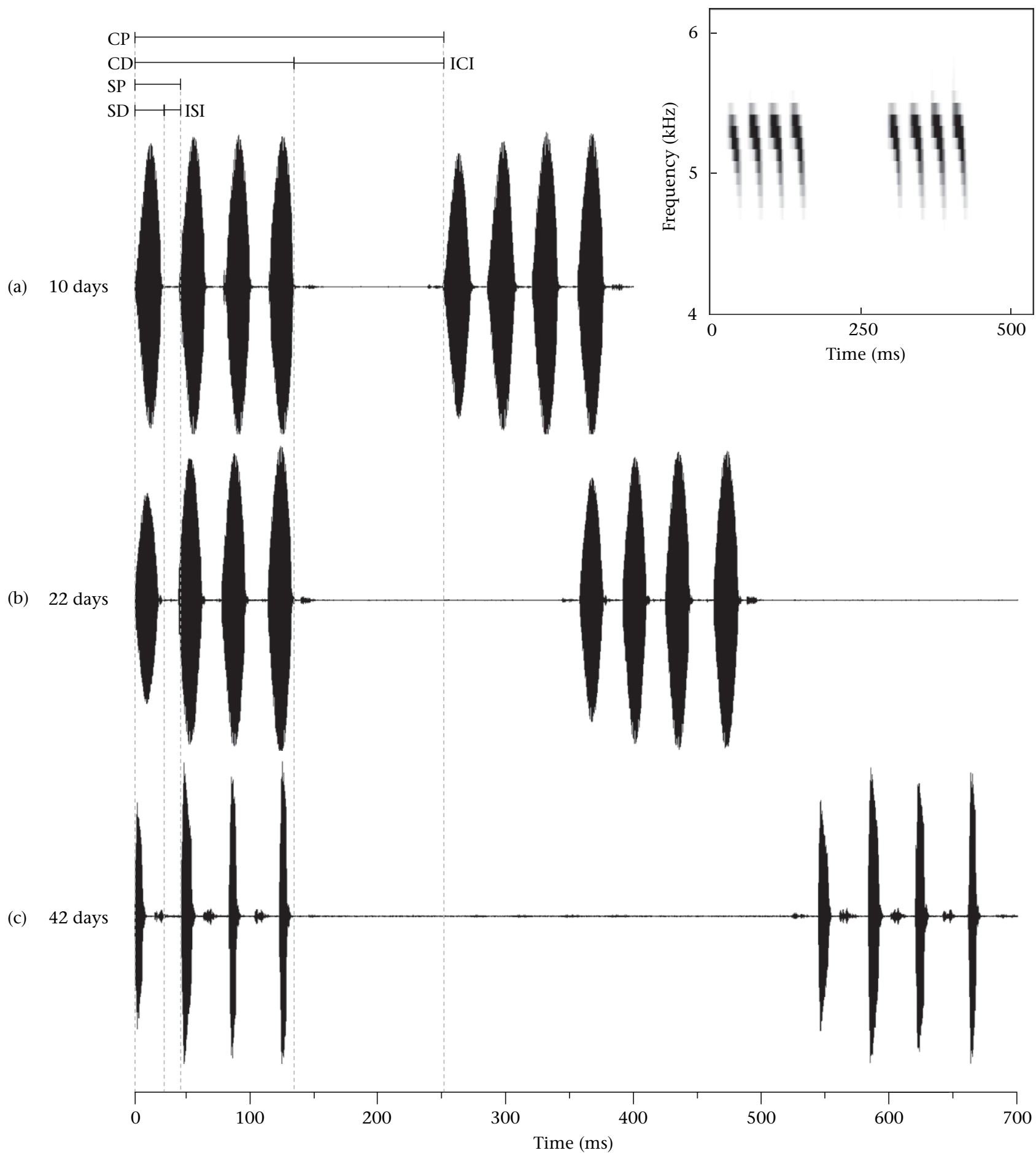

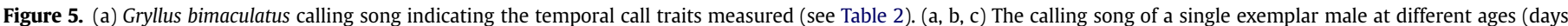
after final moult). Inset: a spectrogram of the song in (a).

from muscle senescence, applied to the tegmina during stridulation is expected to yield only a small decrease in song $\mathrm{FQ}$ as observed in this study and by Jacot et al. (2007), explaining why male field cricket calling song changes in a predictable manner with age. We call our explanatory approach the 'old flight muscle' hypothesis.

Insect flight muscle undergoes age-related losses and/or impairment of mitochondrial functions that result in age-related degradation in flight performance, particularly in flight duration (reviewed in Baker 1976; Sohal 1985). For example, the average size of flight muscle in old individuals is reduced to $13 \%$ of that for young Teleogryllus oceanicus (Ready \& Josephson 1982). Since stridulation probably evolved from flight (Huber 1962), it is not surprising that the thoracic muscles used during flight are the same muscles used for stridulation, where the upstroke and downstroke of flight are homologous to the closing and opening strokes of stridulation, respectively (Bentley \& Kutsch 1966). Age-related degradation of flight muscle performance is therefore expected to affect stridulation. Further support comes from the 


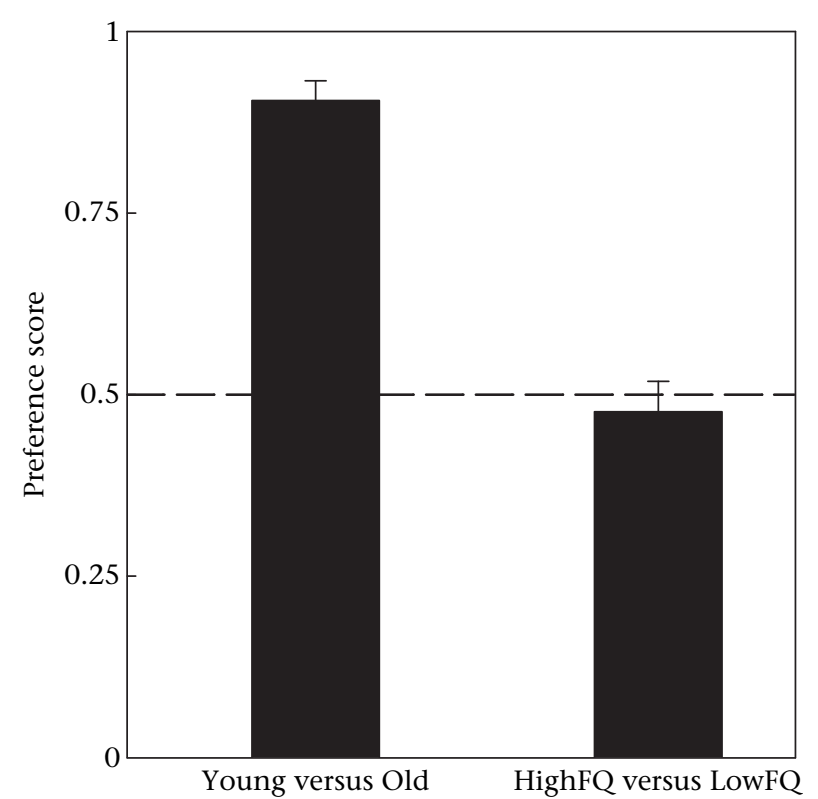

Figure 6. Female preference for male songs in two-choice experiments. Experiment 1: young versus old males $(N=21)$. Experiment 2 : HighFQ versus LowFQ $(N=21)$. A mean preference score of 1 would indicate preference for young male song and songs with a high carrier frequency (HighFQ) for experiments 1 and 2, respectively. Values are means and error bars represent +1 SEM.

well-documented age-related decline in insect metabolic rate caused by decreases in mitochondrial efficiency, protein synthesis and flight muscle performance (reviewed in Sohal 1985). For example, after mass-related effects were controlled for, the standard metabolic rate (SMR, the energetic cost of simple subsistence for a poikilotherm) of house crickets, Acheta domesticus, decreased by $19 \%$ over adult life (7-81 days after final moult; Hack 1997).

The increasingly shorter SD with age provides further suggestive evidence that age-related degradation of muscle performance occurs: weakened muscles may not be able to sustain the force required to complete a full tegmen closure. Production of a song syllable is the energetically demanding portion of the song, as more energy is required to overcome the friction of the plectrum-file interaction than for just tegminal motion alone (Prestwich \& Walker 1981). Shorter syllables are either the result of incomplete closure of the tegmina, where the plectrum does not fully traverse the file, or missing file teeth. Older male bushcrickets, Ephippiger ephippiger, produced slightly shorter syllables owing to missing teeth on the file, which caused slips (Ritchie et al. 1995). On the other hand, worndown file teeth caused by continued use (age) increases the SD in Poecilimon schmidti (Hartley \& Stephen 1989). For G. bimaculatus, we did not observe anomalous syllable oscillograms of older males (e.g. Fig. 5) and post hoc inspection of the right tegminal files from several of our males revealed no missing teeth or obvious tooth wear. Therefore, missing or worn-down file teeth are not likely to explain the observed decrease in SD of our animals.

Our argument is further supported by a slowing down of the song, with age, caused by the increased duration of the silent portions of the song. The ISI and ICI are the silent portions of the song (Fig. 5) during which the tegmina are opened and held stationary for several milliseconds, requiring less energy than syllable production because no friction from tegminal interaction is present (Prestwich \& Walker 1981). Age-related increased ISI and ICI probably reflect a greater recovery time required by weakened muscles before engaging in the next bout of activity. Since chirping, involving silent periods, probably evolved from trilling as an energy conservation measure to achieve longer calling bouts (Prestwich \&
Walker 1981), the increased ICI is probably a mechanism to reduce energetic demands.

The significant increase in the number of syllables per chirp with age at first appears contrary to the 'old flight muscle hypothesis' because an increase in the number of syllables is expected to result in increased energetic investment in the song. However, the decreased syllable duration and increased ICI caused by ageing is so marked that the addition of extra syllables does not compensate sufficiently to maintain the duty cycle (energetic content) of the song, which decreases significantly with age (Table 2, Fig. $3 d$ ). The regression lines in Fig. 3d indicate that males at 50 days of age with four or five syllables per chirp had a lower duty cycle than young males with three syllables per chirp. Indeed, a more rapid decrease of duty cycle with age is observed for five syllables per chirp compared to three syllables per chirp (Fig. 3d), suggesting rapid ageing of the flight muscles with high syllable number. It is likely that males attempt to increase the duty cycle and therefore the attractiveness of their song (see below) by the addition of syllables, because the deteriorating flight muscles are unable to meet the energetic demands of longer syllable durations, but can more easily produce additional syllables per chirp because of the silent ISI which allows the muscles to rest and recover.

\section{Temporal calling activity}

The peak calling activity (acrophase) was not affected by age but male calling activity became increasingly aphasic with age (calling activity dispersion). Older males began calling earlier in the evening (1800 hours) and continued calling for several hours after the onset of the light phase (up to 0900 hours). An explanation for this behaviour is that older males, producing acoustic signals not favoured by females, may increase the probability of attracting females if they call outside of the period when younger, more attractive males are calling (Bertram 2000). Although only eight of 84 female preference trials resulted in the selection of the older song (experiment 1 ), pre-experimental trials $(>10)$ with receptive females always resulted in successful phonotaxis when only the young song or only the old song was played back (single stimulus, no choice), suggesting that older males may attract females if they avoid competing acoustically with younger males.

\section{Body size}

The mean calling activity per day was significantly related to male body size, similar to Gryllus integer (Bertram 2000), while all other song traits were not (see also Verburgt \& Ferguson 2010). Time spent calling has been suggested as the most important call characteristic determining female attraction (Holzer et al. 2003). Large males probably have a fitness advantage over small males. However, this is unexpected from a resource allocation perspective because large males should expend a greater proportion of their daily energy budget on metabolic maintenance owing to higher metabolic subsistence costs (Boggs 2009) and should therefore have less energy available for calling. Greater metabolic heat loss by smaller males (greater surface area:volume ratio) is unlikely to explain why large males can call more, as male G. bimaculatus do not elevate their thoracic temperature significantly above ambient (Toms et al. 1993) as do some tettigoniids (Heath \& Josephson 1970). Irrespective of the energetic mechanism involved, large males are expected to attract more females than small males just by virtue of their capacity to call for longer periods. Since Verburgt \& Ferguson (2010) showed that male body size is not reflected in any structural calling song trait, female preference for large males may be achieved through an indirect process involving longer calling bouts of large males.

\section{Mate recognition traits}

Sexually selected male characteristics are expected to show large degrees of variation between individuals, while mate recognition 
traits should be relatively invariant between individuals and populations owing to stabilizing selection (Paterson 1985; Butlin 1995; Ferreira \& Ferguson 2002). For female G. bimaculatus, song FQ and SP appear to be the two mate recognition traits because certain neurons show distinct maximal sensitivities for these two song traits, which are very similar between individuals (Schildberger et al. 1989 and references therein). Furthermore, the coefficient of variation for these two song traits was significantly lower than for all other calling song traits (Ferreira \& Ferguson 2002). Although SD changed significantly with age, SP remained remarkably stable, resulting in an increased ISI. This provides strong support for the hypothesis that SP is indeed a mate recognition trait (Fig. 3). Male song FQ did change significantly with age, but the change was numerically small $(82.6 \mathrm{~Hz} ;<2 \%)$, being controlled by the escapement mechanism. We demonstrated that this change does not alter song attractiveness for females (Fig. 6), effectively causing the FQ to be stable or invariant from a receiver's perspective. FQ and SP therefore contrast with the other call traits, which were much more variable with age and could comprise sexually selected signals.

\section{Female Preference}

Female crickets in experiment 1 showed a strong and repeatable preference for the songs of young males. In experiment 2, we showed that the change in song FQ with age $(82.6 \mathrm{~Hz})$ does not influence female preference. Furthermore, the fact that females took significantly longer to choose a speaker when songs differed only in FQ (experiment 2) suggests indecisiveness, which could result if both songs appear equally attractive to a receiver. Our results refute the hypothesis that age-related lower song FQ enhances the attractiveness of male calls, which will result in older males being preferentially selected by females (Jacot et al. 2007).

Females probably prefer the songs of young males because the greater energetic quality (shorter chirp period and longer syllable duration) of these songs is likely to provide greater sensory stimulation (reviewed in Ryan \& Keddy-Hector 1992; Gerhardt \& Huber 2002). The duty cycle (proportion of sound within a chirp), which provides a useful measure of energetic quality, was $26.9 \%$ and $17 \%$ for young and old males, respectively (Table 2). Female G. bimaculatus prefer songs of high energetic quality (higher duty cycle) even when chirp period is kept constant (Verburgt et al. 2008) and all female Gryllidae tested (eight species) prefer fast over low chirp rates (reviewed in Gerhardt \& Huber 2002), suggesting a general preference among crickets for greater energetic quality of male song. Because songs of high energetic quality are costly to produce (Prestwich 1994), females are likely to choose not only young males but males able to produce the preferred song.

A possible criticism of our female preference experiments is that for the old male song we used artificial song generated from the mean song trait values of $48-50$-day-old individuals. It is unlikely that G. bimaculatus males will always survive to this age in a natural environment, although several individuals in our laboratory have lived past 120 days after final moult (M. Ferreira, unpublished data) and experiments have been performed on G. bimaculatus previously where males were observed for up to 50 days (Simmons 1988). Nevertheless, Hoikkala et al. (2008) demonstrated that by artificially extending the natural life span of model organisms, relationships between life history variables and age may be exposed that would otherwise not have been clear. Here we have clearly demonstrated that females discriminate against the decreased energetic quality of old male songs. Since this decrease in energetic quality of song was in all cases significantly linearly related to male age, it is reasonable to assume that female preference for male song will also decrease linearly with male age.

\section{Conclusion}

Our results provide a first supporting step for the predictions of Beck \& Promislow (2007) and Velando et al. (2008) using crickets as a model organism. Females showed strong preference for the secondary sexual traits of young males, which decline in attractiveness as they age, probably because of senescence of somatic cells (flight muscles). The female preference results are in contrast to previous field studies where older male crickets were apparently more successful in attracting females (Zuk 1987; Simmons \& Zuk 1992; Simmons 1995). While interspecific differences in mating systems may partially explain this variation in responses (Zuk 1987; Simmons 1995), uncontrolled external influences, which we were able to control for in the laboratory, may partially explain the different results for G. bimaculatus (Simmons \& Zuk 1992). Although no trend emerged from the literature review indicating particular song traits that are affected by age, it is clear that studies finding an effect of age showed decreased energetic investment in song traits with age, which may be explained by degraded muscle performance. The 'old flight muscle' hypothesis therefore appears to have broad application in crickets where changes in song traits with age have been observed. More importantly, our results also show how some signalling traits are not easily susceptible to sexual selection while others are highly variable and open to sexual selection.

\section{Acknowledgments}

We thank Ursula Verburgt for her continuous support. Angela Köhler provided helpful comments on the manuscript. This research was supported by the National Research Foundation (South Africa).

\section{References}

Andersson, M. 1994. Sexual Selection. Princeton, New Jersey: Princeton University Press.

Baker, G. T. 1976. Insect flight muscle: maturation and senescence. Gerontology, 22, 334-361.

Batschelet, E. 1981. Circular Statistics in Biology. New York: Academic Press.

Beck, C. W. \& Powell, L. A. 2000. Evolution of female mate choice based on age: are older males better mates? Evolutionary Ecology Research, 2, 107-118.

Beck, C. W. \& Promislow, D. E. L. 2007. Evolution of female preference for younger males. PLoS ONE, 2, e939, doi:10.1371/journal.pone.0000939.

Beck, C. W., Shapiro, B., Choksi, S. \& Promislow, D. E. L. 2002. A genetic algorithm approach to study the evolution of female preference based on male age. Evolutionary Ecology Research, 4, 275-292.

Bell, A. M., Hankison, S. J. \& Laskowski, K. L. 2009. The repeatability of behaviour: a meta-analysis. Animal Behaviour, 77, 771-783.

Bennet-Clark, H. C. \& Bailey, W. J. 2002. Ticking of the clockwork cricket: the role of the escapement mechanism. Journal of Experimental Biology, 205, 613-625.

Bentley, D. R. \& Kutsch, W. 1966. The neuromuscular mechanism of stridulation in crickets (Orthoptera: Gryllidae). Journal of Experimental Biology, 45, 151-164.

Bertram, S. M. 2000. The influence of age and size on temporal mate signalling behaviour. Animal Behaviour, 60, 333-339.

Bertram, S. M. \& Johnson, L. 1998. An electronic technique for monitoring the temporal aspects of acoustic signals of captive organisms. Bioacoustics, $\mathbf{9}$ $107-118$.

Boggs, C. L. 2009. Understanding insect life histories and senescence through a resource allocation lens. Functional Ecology, 23, 27-37.

Brooks, R. C. \& Kemp, D. J. 2001. Can older males deliver the good genes? Trends in Ecology \& Evolution, 16, 308-313.

Brown, W. D., Wideman, J., Andrade, M. C. B., Mason, A. C. \& Gwynne, D. T. 1996 Female choice for an indicator of male size in the song of the black-horned tree cricket, Oecanthus nigricornis (Orthoptera: Gryllidae: Oecanthinae). Evolution, 50, 2400-2411.

Buffenstein, R., Edrey, Y. H., Yang, T. \& Mele, J. 2008. The oxidative stress theory of aging: embattled or invincible? Insights from non-traditional model organisms. Age, 30, 99-109.

Butlin, R. 1995. Genetic variation in mating signals and responses. In: Speciation and the Recognition Concept (Ed. by M. D. Lambert \& G. H. Spencer), pp. 327-366. Baltimore: Johns Hopkins University Press. 
Cade, W. H. \& Wyatt, D. R. 1984. Factors affecting calling behaviour in field crickets, Teleogryllus and Gryllus (age, weight, density and parasites). Behaviour, 88, 61-75.

Chown, S. L. \& Nicolson, S. W. 2004. Insect Physiological Ecology: Mechanisms and Patterns. Oxford: Oxford University Press.

Ciceran, M., Murray, A.-M. \& Rowell, G. 1994. Natural variation in the temporal patterning of calling song structure in the field cricket Gryllus pennsylvanicus: effects of temperature, age, mass, time of day, and nearest neighbour. Canadian Journal of Zoology, 72, 38-42.

Elliot, C. J. H. \& Koch, U. T. 1985. The clockwork cricket. Naturwissenschaften, 72 , $150-153$.

Ferreira, M. \& Ferguson, J. W. H. 2002. Geographic variation in the calling song of the field cricket Gryllus bimaculatus (Orthoptera: Gryllidae) and its relevance to mate recognition and mate choice. Journal of Zoology, 257, 163-170.

Gerhardt, H. C. \& Huber, F. 2002. Acoustic Communication in Insects and Anurans: Common Problems and Diverse Solutions. Chicago: University of Chicago Press.

Gray, D. A. 1997. Female house crickets, Acheta domesticus, prefer the chirps of large males. Animal Behaviour, 54, 1553-1562.

Gray, D. A. \& Cade, W. H. 1999. Quantitative genetics of sexual selection in the field cricket, Gryllus integer. Evolution, 53, 848-854.

Hack, M. A. 1997. The effects of mass and age on standard metabolic rate in house crickets. Physiological Entomology, 22, 325-331.

Halliday, T. R. 1978. Sexual selection and mate choice. In: Behavioral Ecology: an Evolutionary Approach (Ed. by J. R. Krebs \& N. B. Davies), pp. 180-213. London: Blackwell.

Halliday, T. R. 1983. The study of mate choice. In: Mate Choice (Ed. by P. Bateson) pp. 3-32. Cambridge: Cambridge University Press.

Hansen, T. F. \& Price, D. K. 1995. Good genes and old age: do old mates provide superior genes? Journal of Evolutionary Biology, 8, 759-778.

Hartley, J. C. \& Stephen, R. O. 1989. Temporal changes in the quality of the song of a bush cricket. Journal of Experimental Biology, 147, 189-202.

Heath, J. E. \& Josephson, R. K. 1970. Body temperature and singing in the katydid, Neoconocephalus robustus (Orthoptera, Tettigoniidae). Biological Bulletin, 138, 272-285.

Hoikkala, A., Saarikettu, M., Kotiaho, J. S. \& Liimatainenb, J. O. 2008. Age-related decrease in male reproductive success and song quality in Drosophila montana. Behavioral Ecology, 19, 94-99.

Holzer, B., Jacot, A. \& Brinkhof, M. W. G. 2003. Condition dependent signaling affects male sexual attractiveness in field crickets, Gryllus campestris. Behavioral Ecology, 14, 353-359.

Huber, F. 1962. Central nervous control of sound production in crickets and some speculations on its evolution. Evolution, 16, 429-442.

Jacot, A., Scheuber, H. \& Brinkhof, M. W. G. 2007. The effect of age on a sexually selected acoustic display. Ethology, 113, 615-620.

Jacot, A. Scheuber, H., Holzer, B., Otti, 0. \& Brinkhof, M. W. G. 2008. Diel variation in a dynamic sexual display and its association with female mate-searching behaviour. Proceedings of the Royal Society $B, \mathbf{2 7 5}, 579-585$

Koch, U. T., Elliot, C. J. H., Schaffner, K.-H. \& Kleindienst, H.-U. 1988. The mechanics of stridulation in the cricket Gryllus campestris. Journal of Comparative Physiology A, 162, 213-223.

Kokko, H. 1998. Good genes old age and life-history trade-offs. Evolutionary Ecology, 12, 739-750.

Kokko, H. \& Lindström, J. 1996. Evolution of female preference for old mates. Proceedings of the Royal Society B, 263, 1533-1538.

Loher, W., Weber, T. \& Huber, F. 1992. The effect of mating on phonotactic behavior in the cricket Gryllus bimaculatus (De Geer). Physiological Entomology, 18, 57-66.

Manning, J. T. 1985. Choosy females and correlates of male age. Journal of Theoretical Biology, 116, 349-395.

Marden, J. H. 1995. Evolutionary adaptation of contractile performance in muscle of ectothermic winter-flying moths. Journal of Experimental Biology, 198, 2087-2094.

Martin, S. D., Gray, D. A. \& Cade, W. H. 2000. Fine-scale temperature effects on cricket calling song. Canadian Journal of Zoology, 78, 706-712.

Paterson, H. E. H. 1985. The recognition concept of species. In: Species and Speciation (Ed. by E. S. Vrba), pp. 21-29. Pretoria: Transvaal Museum.

Prestwich, K. N. 1994. The energetics of acoustic signaling in anurans and insects. American Zoologist, 34, 625-643.

Prestwich, K. N. \& Walker, T. J. 1981. Energetics of singing crickets: effect of temperature in three trilling species (Orthoptera: Gryllidae). Journal of Comparative Physiology B, 143, 199-212.

R Development Core Team 2010. R: a Language and Environment for Statistical Computing. Vienna: R Foundation for Statistical Computing. http://www.Rproject.org.
Ready, N. E. \& Josephson, R. K. 1982. Flight muscle development in a hemimetabolous insect. Journal of Experimental Zoology, 220, 49-56.

Ritchie, M. G., Couzin, I. D. \& Snedden, W. A. 1995. What's in a song? Female bushcrickets discriminate against the song of older males. Proceedings of the Royal Society B, 262, 21-27.

Ryan, M. J. \& Keddy-Hector, A. 1992. Directional patterns of female mate choice and the role of sensory biases. American Naturalist, 139, S4-S35.

Scheuber, H., Jacot, A. \& Brinkhof, M. W. G. 2003a. The effect of past condition on a multicomponent sexual signal. Proceedings of the Royal Society B, 270 1779-1784.

Scheuber, H., Jacot, A. \& Brinkhof, M. W. G. 2003b. Condition dependence of a multicomponent sexual signal in the field cricket Gryllus campestris. Animal Behaviour, 65, 721-727.

Scheuber, H., Jacot, A. \& Brinkhof, M. W. G. 2004. Female preference for multiple condition-dependent components of a sexually selected signal. Proceedings of the Royal Society B, 271, 2453-2457.

Schildberger, K., Huber, F. \& Wohlers, D. W. 1989. Central auditory pathway: neuronal correlates of phonotactic behavior. In: Cricket Behavior and Neurobiology (Ed. by F. Huber, T. E. Moore \& W. Loher). Ithaca, New York: Cornell University Press.

Simmons, L. W. 1988. Male size, mating potential and lifetime reproductive success in the field cricket, Gryllus bimaculatus (De Geer). Animal Behaviour, 36, $372-379$.

Simmons, L. W. 1995. Correlates of male quality in the field cricket Gryllus campestris L.: age size and symmetry determine pairing success in field populations. Behavioral Ecology, 6, 376-381.

Simmons, L. \& Ritchie, M. G. 1996. Symmetry in the songs of crickets. Proceedings of the Royal Society $B, \mathbf{2 6 3}, 1305-1311$.

Simmons, L. W. \& Zuk, M. 1992. Variability in call structure and pairing success of male field crickets, Gryllus bimaculatus: the effects of age, size and parasite load. Animal Behaviour, 44, 1145-1152.

Sohal, R. S. 1985. Aging in insects. In: Comprehensive Insect Physiology. Biochemistry, and Pharmacology (Ed. by G. A. Kerkut \& L. I. Gilbert), pp. 595-631. New York: Pergamon.

Sohal, R. S., Mockett, R. J. \& Orr, W. C. 2002. Mechanisms of aging: an appraisal of the oxidative stress hypothesis. Free Radical Biology \& Medicine, 33, 575-586.

Souroukis, K., Cade, W. H. \& Rowell, G. 1992. Factors that possibly influence variation in the calling song of field crickets: temperature, time, and male size, age, and wing morphology. Canadian Journal of Zoology, 70, 950-955.

Toms, R. B., Ferguson, J. W. H. \& Becker, S. 1993. Relationship between body temperature and air temperature in stridulating male crickets, Gryllus bimaculatus (Orthoptera: Gryllidae). South African Journal of Zoology, 28, 71-73.

Trivers, R. 1972. Parental investment and sexual selection. In: Sexual Selection and the Descent of Man 1871-1971 (Ed. by B. Campbell), pp. 139-179. Chicago: Aldine Press.

Velando, A., Torres, R. \& Alonso-Alvarez, C. 2008. Avoiding bad genes: oxidatively damaged DNA in germ line and mate choice. Bioessays, 30, 1212-1219.

Verburgt, L. \& Ferguson, J. W. H. 2010. Mate choice in field crickets: can females acoustically detect male body size? Journal of Ethology, 28, 141-151.

Verburgt, L., Ferguson, J. W. H. \& Weber, T. 2008. Phonotactic response of female crickets on the Kramer treadmill: methodology, sensory and behavioural implications. Journal of Comparative Physiology A, 194, 79-96.

Walker, T. J. 1983. Diel patterns of calling in nocturnal Orthoptera. In: Orthopteran Mating Systems (Ed. by D. T. Gwynne \& G. K. Morris), pp. 45-72. Boulder, Colorado: Westview Press.

Walker, T. J. 2000. Pulse rates in the songs of trilling field crickets (Orthoptera: Gryllidae: Gryllus). Annals of the Entomological Society of America, 93, 565-572.

Walker, S. E. \& Cade, W. H. 2003. The effects of temperature and age on calling song in a field cricket with a complex calling song, Teleogryllus oceanicus (Orthoptera: Gryllidae). Canadian Journal of Zoology, 81, 1414-1420.

van Wyk, J. W. \& Ferguson, J. W. H. 1995. Communicatory constraints on field crickets Gryllus bimaculatus calling at low ambient temperatures. Journal of Insect Physiology, 41, 837-841.

Zahavi, A. 1975. Mate selection: a selection for a handicap. Journal of Theoretical Biology, 53, 205-214.

Zajitschek, F., Bonduriansky, R., Zajitschek, S. R. K. \& Brooks, R. C. 2009. Sexual dimorphism in life history: age, survival, and reproduction in male and female field crickets Teleogryllus commodus. American Naturalist, 173, $792-802$.

Zuk, M. 1987. Variability in attractiveness of male field crickets (Orthoptera: Gryllidae) to females. Animal Behaviour, 35, 1240-1248. 